\title{
The application on EIP-CDIO cultivating model in the course of electronic electrical design classes ${ }^{1}$
}

\author{
Jinfeng Li, Huanle Zhu and Wenjie Zhang \\ Nanchang institute of science \& technology, China
}

Keywords: EIP-CDIO, project driven, education concept, electronic electrical

\begin{abstract}
With the continuous development of today's education career and the changing of social demand for talents, the traditional teaching mode has been difficult to meet the needs of enterprises and society. So, the training mode of college students is faced with huge reform. We need to end the traditional cramming education, and become the teaching mode from students to active to teachers lead and guide. In this paper, the EIP - CDIO engineering education mode is the latest achievements of international engineering education reform in recent years. It has inherited the idea of Europe and the United States for more than 20 years engineering education reform, adaptation of a broader, more conducive to improve the quality. Particularly important is the new standard provides a basis for the systematic. The goal of CDIO teaching mode of is to provide students the engineering education based on the products and systems conceive-design-implement-operate process with a set up in the real world, which emphasizes the engineering foundation. The ability of EIP - CDIO teaching idea advocated include: ability of technical knowledge and reasoning; Individual professional skills and professional ethics; Interpersonal skills: team collaboration and communication; ability of enterprise and social conception, design, implementation and operation. This reflects the unity of systematic, scientific and advanced nature, representing the development trend of modern engineering education. CDIO introduced in this paper represents the organic combination of the conceive, design, implement and operate. EIP is the unity of the Ethics, Integrity and Professionalism.
\end{abstract}

\section{Introduction}

Internationally, since 2000, multinational research composited by four universities of the Massachusetts institute of technology and the Swedish royal institute of technology and so on obtained Knut and Alice Wallenberg foundation nearly \$20 million in huge funding[1][2]. CDIO is the modern university engineering education concept and implementation frameworks which advocated and promoted by the United States the Massachusetts institute of technology, many colleges and universities in the world, at the beginning of the 21st century, namely, conceive, design, implement and operate[3]. In 2005, Swedish National Agency for Higher Education adopts the CDIO standard to evaluate their 100 engineering degree program. In our country, since 2005, Shantou university institute of technology started learning seminars CDIO engineering education mode and implementation[3][4]; December 14-15, 2008, higher education department of the education ministry institute and Shantou university jointly organized the working conference of the CDIO engineering education mode, in the country, a total of 39 colleges and universities in the CDIO pilot work[5]; Since 2011, the pilot in the form of the annual meeting and training communicate research and summarize for CDIO in research and practice work. On January 8-9, 2016, founding conference meeting of "national CDIO engineering education alliance" opened in the in Guangdong Shantou, which hosted by Shantou university, " national CDIO engineering education alliance" reformed on the basis of "CDIO of the ministry of education pilot working group"[6]. Recently, Shantou university decided to CDIO reform also stressed the importance of professional ethics, Shantou university institute of technology, therefore, puts forward the new EIP, CDIO cultivating mode, EIP is refers to the ethics, integrity, professionalism[7].

${ }^{1}$ This paper is funded by teaching reform research subject of Jiangxi province colleges and universities, in 2016.Project number is: JXJG-16-27-10. 
This paper aimed at the university students, electronic and electrical design profession. to study mature, remarkable achievements or according to need, this teaching method can implement in the other practical professional, seeking maximum benefit for students. Through exploration and practice of cultivation mode for students of electrical engineering, to improve the university students' the quality of personnel training, so that the students can have strong ability of project development[6]; To make a full set of training scheme for electrical engineering, not only improve project development innovation ability of students, more to improve the professional quality of students, cultivate a batch of talents of electrical engineers, truly with social enterprises. In the EIP CDIO teaching mode, the project driven teaching has formed a "project as the main line, teacher as guide and students as the main body" the basic characteristics, must not use the traditional "one pole, cramming education" with teachers as the theme of the teaching mode.

\section{The main content}

This paper will focus on the EIP - CDIO teaching new concept combined with the school of electrical courses, driven by the project of teaching mode, in order to improve the students' vocational quality and engineering project design ability as the main content.

1) Analysis of EIP-CDIO teaching new concept and its application goes on in the project driven teaching of modern university engineering.

CDIO representative Conceive, Design, Implement and Operate four parts, it put life cycle of product research to the product's development as the carrier, to let the students to actively, practice, course organic connection to study engineering. The aim of CDIO training mode is to improve graduates' engineering knowledge, personal ability, interpersonal ability and ability of engineering' systems, it requires that the students are in graduate with the four capacities. Because our country is deficient in the professionalization and professional ethics education, this paper focuses on new EIP-CDIO cultivating pattern, making the morality, honest and professional and Conceive, design, implement, operate to carry on the organic combination.

2) The students as the main research object, the statistical analysis of the students' project practice ability and the improvement of professional quality. With teachers as the guide, university-enterprise cooperation projects as the main line, teaching mode based on the EIP - CDIO is the main idea in the relevant professional teaching in full swing in the active project drivers.

3) Making our current courses in electronic electrical class as the research sample. And extension of the class as the center to the related courses, we expand the scope of research, and to integrate with the society, produce more applied talents.

Our current courses in electronic electrical design class has great practicability and practicality, EDK design software (Multisim and Protel, etc.) mainly used matching the related enterprise software used, more conducive to constructing university-enterprise cooperation platform, easier to drive the teaching implementation project.

4) We will build the EIP - CDIO high-quality practical talents cultivation mode and evaluation system of electrical engineers. It is guided by hardware simulation engineering design, engineering ability training as the goal, through the project design combining the whole course system with organic and systematic.

At present, the school personnel training mode of electrical engineers is not unified, different teachers having different teaching methods, different emphasis, different assessment standard and effect. So, to integrate with the society, to develop a high-quality talent training mode is very meaningful, personnel training mode needs the guide of modern education theory and education ideology, specific training goals and talents according to specifications, with relatively stable teaching contents and curriculum system, management system and evaluation methods, the implementation of talent education.

5) Constructing university-enterprise cooperation platform. Teachers will make classroom knowledge into enterprise work task, letting the students to join a specific project development process, the whole process of training high quality innovative talents.

The premise of successful implementation of project driven teaching mode is to select suitable 
for their projects successfully according to the students' existing knowledge, level and experience and interest. The key of the project driven teaching is leading the study of the course with the advancement of the project in the whole teaching process and layers of in-depth, driving the development of classroom teaching. Under the guidance of teachers, students naturally learn new knowledge through continuous exploration and solve problems independently, finding and solving problems the ability training. In the entire project implementation process we should not only improve students' ability of conception, design, implementation, operation, more to improve the students' moral quality, integrity, and professionalism.

As shown in figure 1, EIP CDIO teaching mode in electronic electrical course includes the EIP education, the CDIO education and project driven. Among them, the professional ethics education includes morality, honesty and professional education; the cycle of product, process or production is the life cycle of conception, design, implementation and operation; the process of projects driven is the determination of project objectives, demand analysis, scheme design, project implementation and effect evaluation and improvement. The EIP - CDIO teaching mode has five main content methods, four target achievement, they complement each other.

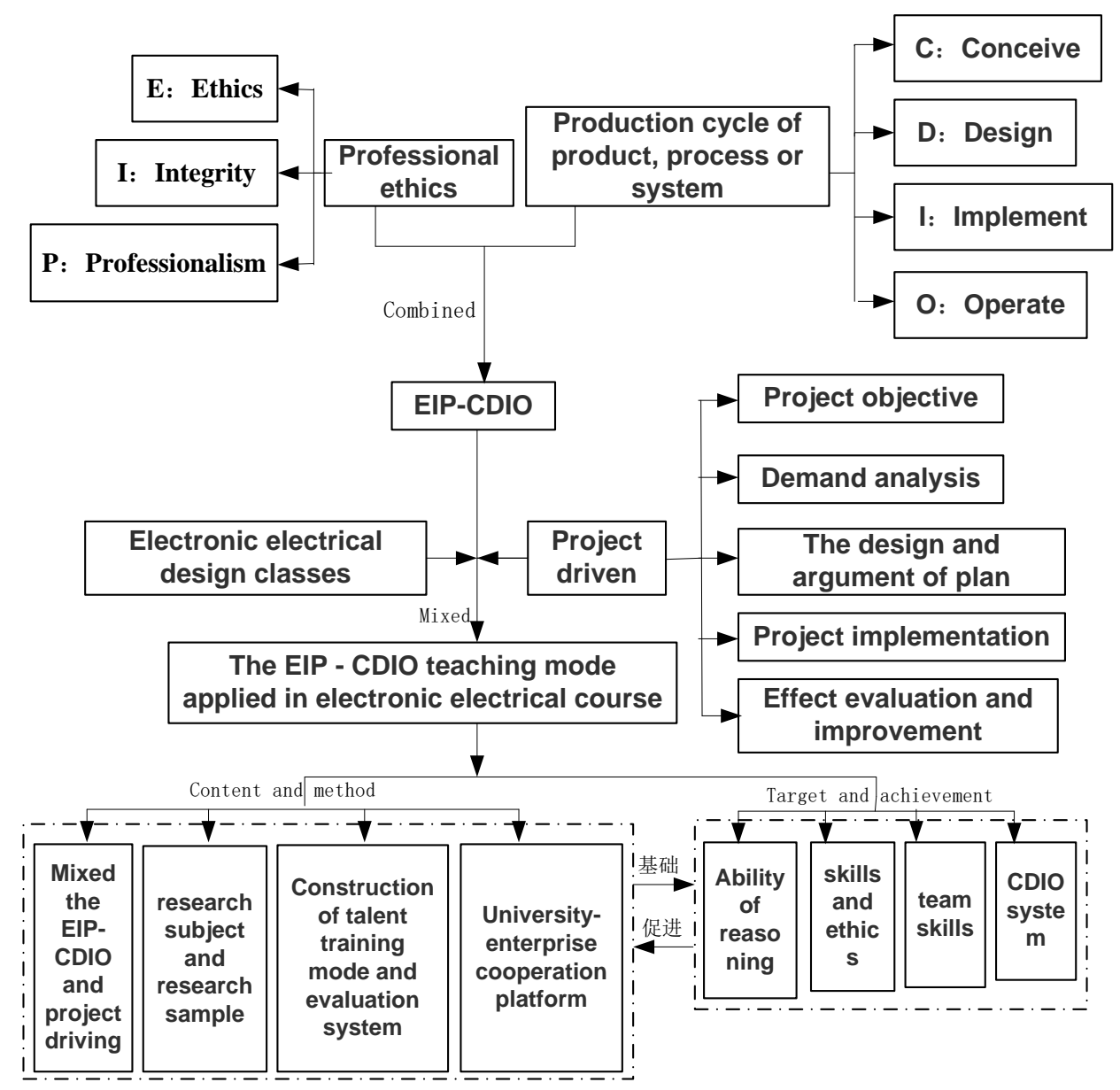

Fig.1. the research content and target

\section{Advantage and feature of EIP, CDIO cultivating mode}

EIP - CDIO pay attention to the organic combination of ethics, integrity, professional and conceive-design-implement-operate, the goal of this new mode of higher engineering education is to train senior engineering talents.

First of all, through to explor and practice training mode of electronic electrical professional, we will make the EIP-CDIO cultivating plan scientifically, improving the quality of talent training, to make the students have stronger ability to project development, design and construction.

Second, we need to improve the students' innovation ability, communication ability and team 
work spirit. Produce more talents of electrical engineers in line with the social demand, thus, we can provide personnel training mode with a kind of electronic electric can be drawn lessons for other universities.

Once again, we need to improve students' learning enthusiasm and initiative. In this thesis, we mainly make classic case of university-enterprise cooperation projects as the object of implementation, analog electronic circuit design project development environment, learning in the thinking, development and innovation in the study.

Finally, we need to improve the students' practical operating, leadership and professional quality of the students, and honest. Team spirit to meet the demand of today's society for applied talents, to integrate with the society, schools can cultivate a batch of practical talents.

\section{Conclusion}

In order to the smooth implementation of EIP-CDIO cultivating mode, teachers need to do a lot. First of all, a person combined with work. Second, we need to inspire students' enthusiasm to participate in practice. Third, we should train students' team cooperation consciousness. Fourth, we need to build the applied talent cultivation plan of electrical engineers and personnel training evaluation system. In a word, students as the center, placing students in the search for knowledge context is the basis to research EIP-CDIO teaching mode. We must change ideas, establish effective teaching team and construction team. It is good for students to establish self-confidence, the social organic fusion, effectively realizing the unity of knowledge and ability, make up a solid foundation for future development.

\section{References}

[1] Hongying Zhu, Pinhua Lai, Xiaoman Gong. Development and construction of Java curriculum and DACUM model research based on projects driven[J]. Journal of science and technology, ISTIC PKU 2014.11.

[2] Xuerong Yang, Siyuan Cheng, Zhongning Guo. Teaching reform and practice of reverse engineering technology based on the autonomous driven project[J]. Journal of the experiment technology and management, ISTIC PKU - 1, 2016.

[3] Guoyan Yu, Gui Wang, Huanlao Liu, Fenju An, Juan Zhao. Mechanical engineering exploration and practice of collaborative project teaching practice mode[J] Journal of China university teaching, PKU CSSCI 2014-12.

[4] Qin Cai, Kai Zhang. Application of project driven teaching model in the engineering teaching of software[J]. Journal of experimental science and technology, 2014.4.

[5] Li Li, Gang Chen, Xuelian Tian. Application of project drivers in the "digital signal processing" course teaching[J]. Journal of laboratory research and exploration, PKU, 2015.12.

[6] Jinfeng Li, Huanle Zhu, Wenjie Zhang. Application study of project drivers in "electronic circuit design and simulation" in classroom teaching[J]. Journal of bosom friend inspiration, 2016.04.

[7] Jinfeng Li, Wenjie Zhang. Professional quality of preparatory teachers in the classroom under the new situation[J]. Journal of hundreds prose, 2015.06. 